\title{
REVISITING PROTOTYPING IN 2020: A SNAPSHOT OF PRACTICE IN UK DESIGN COMPANIES
}

\author{
Goudswaard, Mark (1); \\ Gopsill, James (1,2); \\ Harvey, Mike (1); \\ Snider, Chris (1); \\ Bell, Andy (3); \\ Hicks, Ben (1) \\ 1: Design and Manufacturing Futures Lab, University of Bristol; \\ 2: Centre for Modelling and Simulation (CFMS); \\ 3: University of Sheffield Advanced Manufacturing Research Centre (AMRC)
}

\begin{abstract}
The importance of prototyping is unanimous with numerous studies into the media, types, roles and properties of prototypes. However, no recent papers have sought to examine and characterise industry practice and if and how this has changed since the early 2000 s.

To address this, a snapshot of industrial prototyping practice with particular attention to the what, when, why, how, and by whom is reported. The study involved five small-medium sized design companies based in the South-West of the UK and validation of the findings by two independent practitioners.

The snapshot revealed that 3D printing and virtual prototyping tools have reached widespread adoption in SMEs, that their design processes are highly agile and iterative and are difficult to fit to any extant design process model.

Rather, the approaches appear to implicitly comprise of three levels of design convergence: macro, meso, and micro, which correspond to finer/more detailed changes.

The results also reveal the frequent transitions between digital and physical media and the need to manage these transitions to ensure the product representations in different media are appropriately upto-date.
\end{abstract}

Keywords: Design practice, Design process, New product development

\section{Contact:}

Goudswaard, Mark

University of Bristol

Mechanical Engineering

United Kingdom

mg0353@bristol.ac.uk 


\section{INTRODUCTION}

Prototyping plays an important and fundamental role in design (Houde and Hill, 1997). As a result, research has sought to develop optimal prototyping strategies (Camburn et al., 2017; Elverum et al., 2016; Jensen et al., 2016), characterise the benefits of prototyping (Coutts et al., 2019; Mathias, Hicks, et al., 2018), and create new/improved prototyping media (Felton et al., 2020; Mathias, Snider, et al., 2019; Yamaoka et al., 2019). With such ongoing change it is crucial to capture their effect and the state of prototyping practice in industry, to ensure that design research continues to deliver innovations that can be pulled through. Studies such as Wall et al. (1992), Yeomans et al. (2006), and Zorriassatine et al. (2003), have provided valuable snapshots of industry prototyping practice with approximately 500 combined citations ${ }^{1}$ demonstrating their utility to the community, where a snapshot comprises a study that characterises the state of an element of engineering practice at a point in time (Arcuri and Briand, 2011; Graham et al., 2009; Gregory, 1993; Hornbæk, 2006). However, the most recent snapshot was in 2006 which is over a decade ago. Since then, prototyping methods, tools, and technologies have continued to advance in both digital (e.g., widespread 3D modelling uptake and advanced simulation) and physical domains (e.g., widespread adoption of low-cost 3D printing (e.g., Fused Deposition Modelling - FDM)). Given that tools have already evolved - and hence so has the workflow - how widespread is their adoption, what exactly are the changes to prototyping processes, and what are the new challenges and opportunities that they afford? The contribution of this paper is in provision of a snapshot of industry prototyping practice in 2020. By placing a focus on the technological workflow and process followed in current practice, this paper facilitates comparison of the current vs. previous snapshots, in order to understand trends of evolution and identify the challenges and opportunities for the design research community to support industrial prototyping practice.

This is achieved by characterising prototyping activities and identifying how they are supported by prototyping tools via a survey of Design Small-to-Medium Enterprises (SMEs). The paper begins with a summary of the previous snapshots that have characterised prototyping practice in the years 1992, 2003, and 2006 (Section 2). This is followed by the capture methodology and a summary of the five participating design companies (Section 3). The results are then summarised to form a snapshot (Section 4), and the findings presented with respect to the similarities, contrasts, and characteristics, and their fit with existing design process models. The snapshot of current practice and changes it portrays are validated by independent design practitioners in Section 5 which also highlights implications of the observed practice(s) for design research.

\section{SNAPSHOTS OF PRACTICE IN THE 905 AND OOS}

Three seminal papers were identified through triangulation of results from Google Scholar, the Design Society, Research in Engineering Design and the Design Studies journals. Each provides a snapshot based on the context of design studied, number of participating companies and the lens that they used to examine prototyping practice.

Wall et al. (1992) analysed the prototyping practices of Eastman Kodak Company; specifically, via the plastics components they intended to produce. The study involved participants providing details of the attributes each prototyping tool afforded. The prototyping tools used were Computer Aided Design (CAD) drawings, Stereolithography (STL) Additive Manufacturing, Computer Numerical Control and Rubber Moulding. It became quickly apparent that multiple tools were required to provide knowledge and confidence to take a product forward to production. Challenges lay in variation of lead times and costs (typically $\$ 1000+$ per prototype), associated with varied toolchains requiring thorough planning and optimal process combinations to ensure a project could be delivered to time, cost and quality. Zorriassatine et al. (2003) present a survey of mechanical product development organisations. The lens focused on virtual prototyping tools and methods, revealing that virtual prototyping was very much in ascendance at the time. Adoption was present in large companies whilst SMEs were still in the uptake phase, attributed to the significant investment required when such technologies are first implemented. It also revealed that virtual prototyping had advanced beyond conveying form and geometry to visualising form and geometry with renders, analysis of fit between assemblies,

\footnotetext{
${ }^{1}$ Using Google Scholar citation metrics.
} 
simulations that could test and validate performance and evaluation and feedback on manufacturability. It also highlights a tension between the importance of concurrent engineering but tools only permitting disciplines to interact sequentially rather than collaborate synchronously through the design process.

Yeomans et al. (2006) focused on collaborative prototyping practice across architecture and civil engineering. Prototyping practice was increasingly being used to facilitate multi-stakeholder engagement and feedback on designs (26\% of prototyping activity). Virtual prototyping was reaching the sector with $51 \%$ using 3D CAD. The tools facilitated collaborative prototyping as designers could provide client user journeys via virtual walks of their designs, although only at component level (e.g. individual floors) rather than a system-level (e.g. entire building and surrounding geography). Again, the uptake of virtual prototyping tools had reached the large organisations but not the SME sector. Manufacturing process simulation for the industry was still under development.

The three snapshots provide, some interesting insights that may be surprising to the community. The first is the application of Additive Manufacturing Rapid Prototyping tools in the early 90s. While it may have been only the largest product development organisations, it does provide an interesting indicator to the lead times for such technologies to become commonplace. The second is in the rise of virtual prototyping with each snapshot showing the continued increase in capability of the virtual domain to meet our prototyping needs. The third is prototyping as a collaborative design activity with multiple stakeholders being able to communicate their ideas across a common intermediary object. These insights present interesting trends for the design research community (as will be discussed further in Section 5), but are bound to their time of creation. To present updated insights that account for the extant changes in technology and process of the last 10 years, this paper presents the generation of a new snapshot.

\section{METHODOLOGY}

To generate a snapshot of practice in 2020, the applied methodology consisted of an initial visit to familiarise with each company and their form of design work, followed by distribution of a survey to a senior stakeholder to complete. The survey consisted of a questionnaire comprising of eleven questions aimed at: defining what each company prototypes; identifying when in their design process they undertake prototyping activities; and, exploring why, how, and by whom activities are carried out.

Questions were written by three experienced engineering design researchers at the University of Bristol based on their knowledge and understanding of the field and the organisations who participated. Survey questions are shown in Table 1. To aid response to questions where time/process is of critical interest, respondents were provided with a timeline to complete against (as demonstrated by the question response in Figure 1).

No time restrictions were given on completing the questionnaire and responses were either returned in person or via email. Table 2 provides details of the participating organisations. Five companies participated, together spanning engineering design technical sectors and with each including prototyping as a core part of their process.

Table 1. Survey questions. Entries marked with * provided respondents with a timeline to sketch their response on to indicate where in the process they occurred.

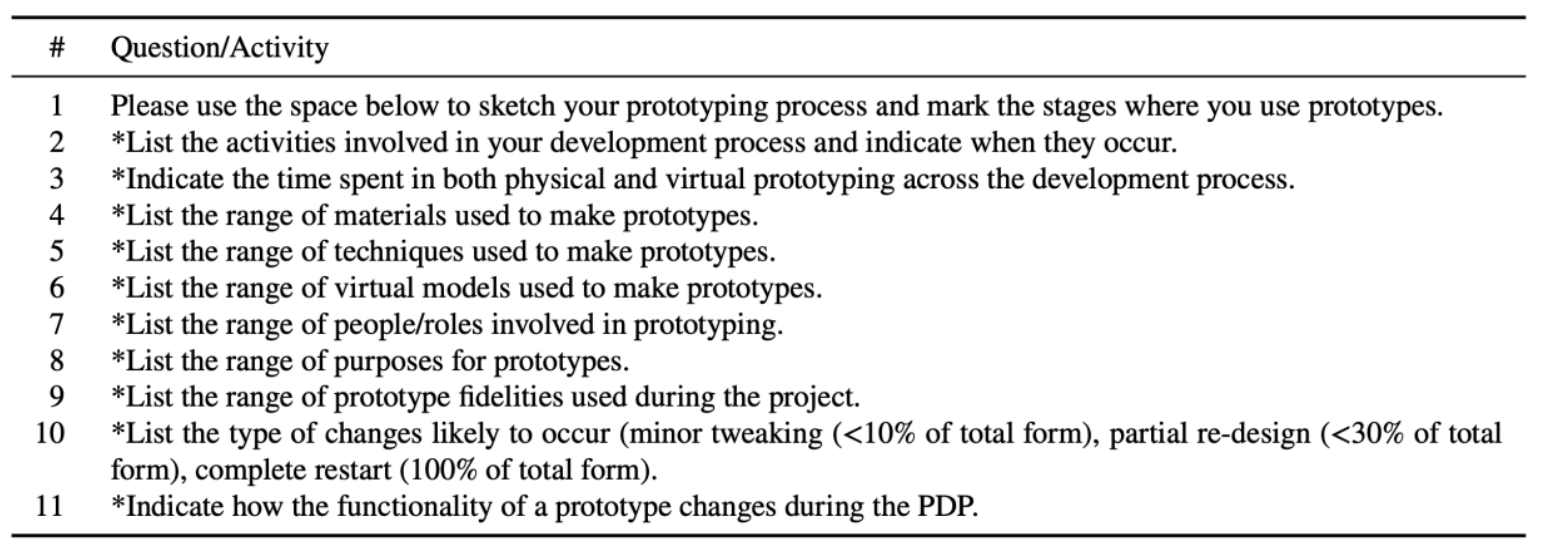




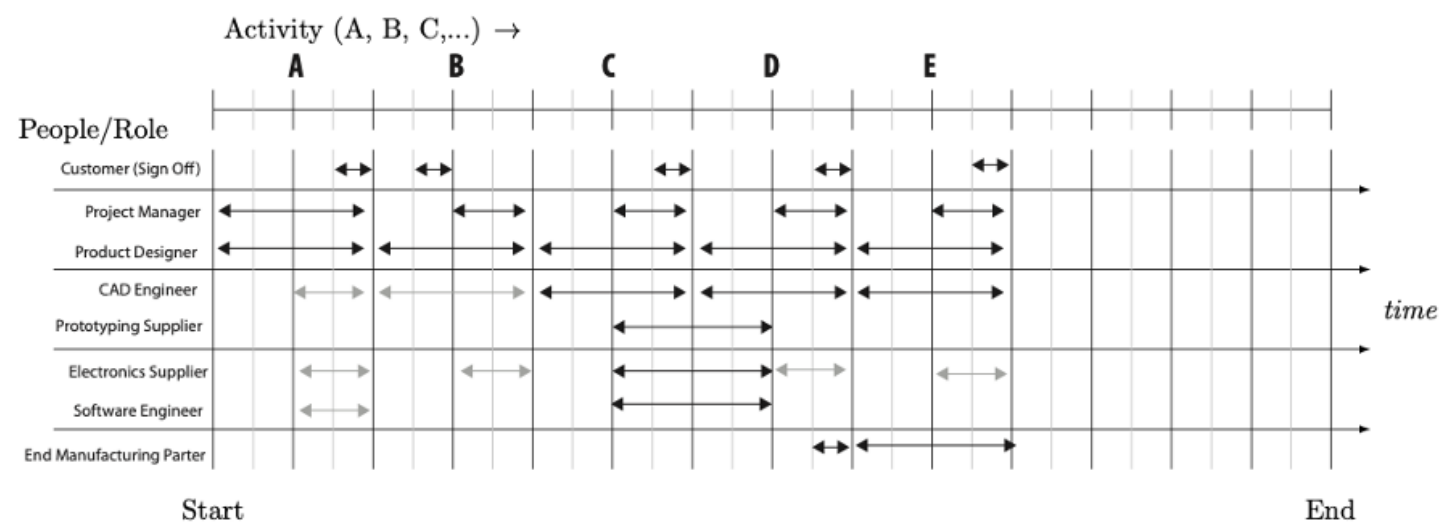

Figure 1. People in prototyping $Q 7$ response from company $B$ completed on timeline provided.

Table 2. Summary of companies surveyed.

\begin{tabular}{|c|c|c|c|c|c|c|}
\hline Company & Field & Location & Size & Turnover & Age & $\begin{array}{l}\text { Seniority of survey } \\
\text { respondent }\end{array}$ \\
\hline A & Model Maker & Bristol & $30-40$ & $£ 2-3 \mathrm{M}$ & 1984 to present & $\begin{array}{l}\text { Owner/director with } 40 \\
\text { years' experience }\end{array}$ \\
\hline B & Design Consultancy & Bristol & $5-10$ & $£ 0.5-1 \mathrm{M}$ & 1999-present & $\begin{array}{l}\text { Manager with } 10 \text { years' } \\
\text { experience }\end{array}$ \\
\hline $\mathrm{C}$ & $\begin{array}{l}\text { Bicycle } \\
\text { Manufacturer }\end{array}$ & Wiltshire & $10-20$ & $£ 0.5-1 \mathrm{M}$ & 2008 - present & $\begin{array}{l}\text { Technical Director. with } 25 \\
\text { years' experience }\end{array}$ \\
\hline D & $\begin{array}{l}\text { Design } \\
\text { manufacture } \\
\text { disability aids }\end{array}$ & Bath & $20-30$ & $£ 1-2 \mathrm{M}$ & 1968 - present & $\begin{array}{l}\text { Mechanical Design engineer } \\
\text { with } 6 \text { years' experience }\end{array}$ \\
\hline $\mathrm{E}$ & $\begin{array}{l}\text { Electronic Design } \\
\text { Service }\end{array}$ & Bristol & $10-20$ & $£ 1-2 \mathrm{M}$ & 2012 - present & $\begin{array}{l}\text { Operations Director with } 10 \\
\text { years' experience }\end{array}$ \\
\hline
\end{tabular}

\section{RESULTS}

The results from the surveys are shown in Table 3 and Table 4. The following summarises the key features of the design and prototyping processes of each company surveyed. Each summary is linked back to the question that provides this information. For example, Q1A refers to company A's response to question 1. Statements not directly referring to a survey question came from the stage one discussions with the companies.

\subsection{Company A}

The following key features can be elucidated from company A's survey response. First, it is notable how important iteration is in the design process and that design reviews $(\mathrm{Q} 1 \mathrm{~A})$, both internal and with clients (Q7A), are an integral part of this. This is in part due to design change being directed by the customer. The design process also features a range of roles undertaken by different stakeholders that contribute specialist knowledge towards the process and product (Q7A). Prototyping is shown to occur iteratively between both physical and virtual domains (Q3A). The physical prototyping methods can be seen to occur in three phases based on increasing level of tooling: 3D printing, soft tooling and real tooling - featuring both machine and hand tooling (Q5A).

\subsection{Company B}

In a similar manner to A, B demonstrates how design reviews are integral to the design process (Q1B) and feature distinct roles and stakeholders (Q7B). It is also noteworthy to see electronics suppliers included in the process indicating the importance of external stakeholders in the design process (Q7B). Additional similarities can be seen with a three-phase physical prototyping process; first development with $3 \mathrm{D}$ printing, then detailed design with vacuum casting followed by design for manufacture with real tooling (Q5B). B's process also features high levels of iteration and parallel digital and physical working but for relatively low levels $(<10 \%)$ of product changes $(\mathrm{Q} 5 \mathrm{~B}, \mathrm{Q} 10 \mathrm{~B})$. Major changes are noted to be rare due to tight requirements specifications and problem definition earlier on in the project (Q10B). 


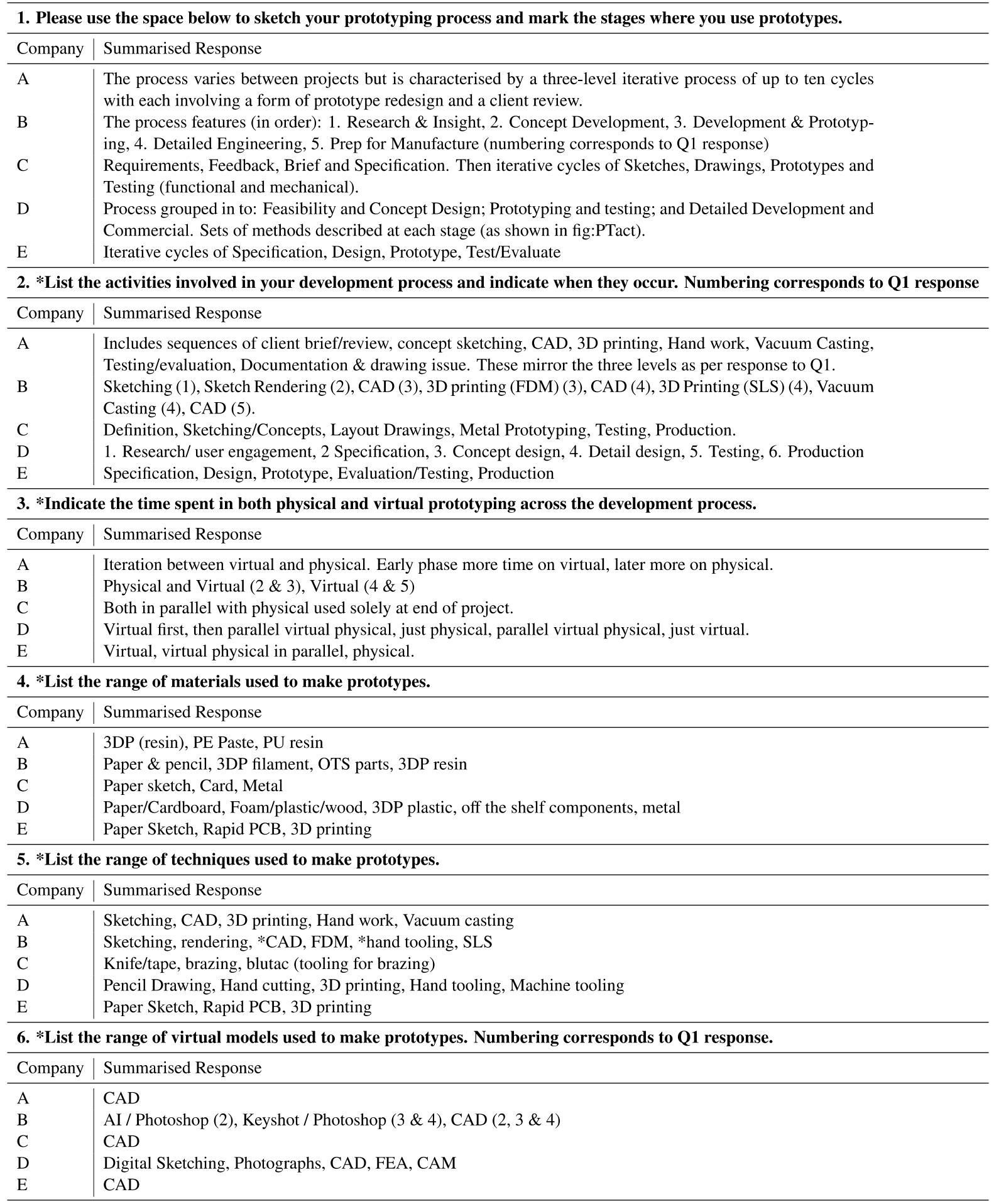

\subsection{Company C}

$\mathrm{C}$ also demonstrates a highly iterative design process (Q1C) with separation of roles and multiple stakeholders involved in the process (Q7C). In contrast to A and B, C's prototyping methods are largely physical sometimes going direct from sketch to metal (Q5C). This direct fabrication in metal could, in part, be attributed to a high number of technicians and workshop staff on site to make parts and a single designer. This single designer could also result in the comparatively lower use of digital prototyping methods as there is less necessity for documented changes and checker/approver processes 
as design is carried out more cognitively and only for a single product. It is also noteworthy that $\mathrm{C}$ sell their product direct to customers as opposed to serving as a design consultancy.

Table 4. Survey responses to Q7-Q11 Roles in Prototyping. Order listed corresponds to order in the process. Processes marked * are iterative/recurring.

\begin{tabular}{|c|c|}
\hline \multicolumn{2}{|c|}{ 7. *List the range of people/roles involved in prototyping. } \\
\hline Company & Summarised Response \\
\hline A & Client*, CAD designer*, Maker, Casting Technician. \\
\hline B & $\begin{array}{l}\text { Customer*, Project manager*, product designer (involved throughout), CAD engineer, prototyping supplier, } \\
\text { electronics supplier, software engineer, end manufacturing partner }\end{array}$ \\
\hline $\mathrm{C}$ & Team, Customer*, Designer (involved throughout), Tester \\
\hline $\mathrm{D}$ & $\begin{array}{l}\text { Customer, Product Designer, Design Engineer (involved throughout), Workshop Technician, Sup- } \\
\text { plier/Manufacturer }\end{array}$ \\
\hline $\mathrm{E}$ & CAD Engineer, Electronics Engineer, Customer* \\
\hline \multicolumn{2}{|c|}{ 8. *List the range of purposes for prototypes. } \\
\hline Company & Summarised Response \\
\hline A & $\begin{array}{l}\text { Very project dependent. Typically first prototypes are used to prove out any mechanisms, dimensionally ac- } \\
\text { curate form focussed prototypes then follow. From here a range of versions follow refining proportions and } \\
\text { functionality at each step. }\end{array}$ \\
\hline B & Concept (looks like) (1), MVP (3), Functional prototype (3\&4), Final product (4\&5) \\
\hline $\mathrm{C}$ & Fit (beginning and end of process), Function (throughout) \\
\hline $\mathrm{D}$ & Proof of principle, looks/feels like, functions like, materials and mechanisms proof, pre-production sample. \\
\hline $\mathrm{E}$ & Looks like, the functions like \& looks like \\
\hline \multicolumn{2}{|c|}{ 9. *List the range of prototype fidelities used during the project. } \\
\hline Company & Summarised Response \\
\hline A & $\begin{array}{l}\text { Project dependent. Typically low fidelity prototypes to start, increasing through the design process as propor- } \\
\text { tions, materials and functionality are refined. }\end{array}$ \\
\hline B & High fidelity throughout. \\
\hline $\mathrm{C}$ & $\begin{array}{l}\text { Progressive and arrives to approx. } 90 \% \text { of final product quickly. Non-concurrent development also occurs } \\
\text { outside of product cycles. }\end{array}$ \\
\hline $\mathrm{D}$ & $\begin{array}{l}\text { Space / volume, basic interactions and aesthetics, functional and usable, developed functions \& stronger, pro- } \\
\text { duction ready }\end{array}$ \\
\hline $\mathrm{E}$ & Space model, limited function, finished product \\
\hline \multicolumn{2}{|r|}{$\begin{array}{l}\text { 10. * List the type of changes likely to occur (minor tweaking }(<10 \% \text { of total form), partial re-design } \\
(<30 \% \text { of total form), complete restart }(100 \% \text { of total form). }\end{array}$} \\
\hline Company & Summarised Response \\
\hline A & Project dependent. \\
\hline $\mathrm{B}$ & Prototypes rarely change their form unless due to customer request. \\
\hline $\mathrm{C}$ & Minor change to form throughout the process but most likely in early phases. \\
\hline $\mathrm{D}$ & Minor changes throughout, partial changes in first $2 / 3 \mathrm{~s}$ of project, total changes in first $1 / 3$. \\
\hline $\mathrm{E}$ & Minimal form change - around $20 \%$ average change between prototype and finished product. \\
\hline \multicolumn{2}{|c|}{ 11. *Indicate how the functionality of a prototype changes during the PDP. } \\
\hline Company & Summarised Response \\
\hline A & Project dependent. \\
\hline $\mathrm{B}$ & Functionality evolves on ad-hoc basis dependent upon customer requests or new user insights. \\
\hline $\mathrm{C}$ & Functional development is typically non-concurrent. Prototypes are therefore typically $80-100 \%$ functional. \\
\hline $\mathrm{D}$ & Barely functional, simulated functionality, partial functionality, fully functional. \\
\hline $\mathrm{E}$ & Technology Demo, Limited Function, Final Product. \\
\hline
\end{tabular}

\subsection{Company D}

D's design process shows largely concurrent digital and physical prototyping processes (Q3D). Digital processes include a range of modelling and analytical tools (Q6D). Like the other companies, separation of roles can be seen and these evolve in parallel with prototype functionality through the design process (Q7D). D uses a range of physical prototyping techniques at different stages to meet requirements of individual prototypes in terms of fidelity and to understand user needs (Q5D). D sells ISO accredited assistive technology products directly to the customer and have large project teams 
necessitating a more advanced and formal design process as demonstrated by their survey responses (Q1D). The design team are able to undertake major changes late in the process if necessary due to the products designed by $\mathrm{D}$ being highly bespoke with low production volumes. This is supported by a non-profit arm of the business.

\subsection{Company E}

Similar to all other companies, E demonstrated a highly iterative design cycle (Q1E) with separated roles with distinct purposes (Q7E) through the design process. In contrast to the other companies, all design iterations are virtual with a physical product (e.g. PCB) only necessary to verify properties (e.g. thermal) (Q5E). This largely virtual process is due to industry standard toolsets, such as PSpice, and tight regulation meaning that designs are highly constrained and can be fully simulated.

\subsection{Snapshot of Practice}

From each company's summary a number of general characteristics and comparisons can be observed forming our snapshot of current prototyping practices in the surveyed companies.

- A similar observation across the surveys is the prominence of iteration within the companies' design processes (Q1). All companies demonstrated highly iterative processes with varying levels of change from major to minor (Q10, Q11). These iterations culminate individually or collectively in design reviews that can be considered as stakeholder crossroads in the development process. To support and have effective design reviews, design iterations need to be captured to justify how and why designs have evolved and changed.

- The prominence of prototyping techniques of 3D printing and vacuum forming can also be observed (Q5), confirming the technological change that predicated this survey, as discussed in Section 2.

- In all companies, a wide range of stakeholders can be observed to be part of the design process (Q7), contributing in different ways according to their expertise. The quantity and roles of these can be seen to influence the amount of iteration that takes place - more stakeholders with more diverse roles result in more iteration, particularly when the user/customer is in the loop and their requirements may necessitate larger design changes.

- The level of formalisation of design processes depends on the size of the design team and whether supplying a final product to customer. The contrast can be seen with the larger teams of D \& E with the small design team in $\mathrm{C}$. The survey results indicate that larger design teams (Q7) require formalisation to work together effectively, whereas a single designer is able to work effectively via their own cognitive design process (Q1 \& Q2).

- The relative levels of digital and physical depends more on type of product and cost of non-quality. Extremes on this spectrum are $\mathrm{C}$ with pure physical vs E's pure digital prototyping processes. Other companies used a combination of digital and physical (Q3). The value, complexity and variety of projects appear to correlate with the number different prototyping techniques and level of formalisation and complexity of process.

\section{DISCUSSION}

To consider the implications of the snapshot presented in the previous section, this discussion section i) compares our current snapshot with previous snapshots, ii) presents a validation of the snapshot by additional practitioners, iii) explores fit of practice with existing models and iv) identifies how prototyping can be improved and further work.

\subsection{Comparison of current practice with literature}

Comparing our new snapshot with those presented in previous literature highlight a number of key features. First, the use of digital \& physical prototyping methods is commonplace across the companies surveyed, demonstrating maturity of virtual prototyping methods. Whilst literature showed full virtual prototyping processes as an avenue of great potential (Zorriassatine et al., 2003), the reality revealed by our snapshot is that they need to be carried out in combination with physical prototyping, as each domain holds benefits that need to be leveraged (see survey Q5). In parallel with this, the survey results demonstrate widespread acceptance and use of 3D-printing in the prototyping processes where previously SMEs had not fully adopted these technologies. 
The survey results also demonstrate highly iterative processes with extensive transition between digital and physical prototypes throughout the process. This could be enabled by widespread acceptance and deployment of both AM and virtual prototyping tools. The iteration facilitates more concurrent, higher frequency input from stakeholders in the design process - whereas previously stakeholders would have to interact sequentially (Zorriassatine et al., 2003).

\subsection{Validation by practitioners}

The findings of the snapshot were validated by two additional experienced practitioners with over 60 years combined design experience. This was carried out in the form of a semi-structured interview. The findings of these are summarised as follows.

On use of 3DP in prototyping: 3DP has come of age in the last 15 years with office-friendly rapid physical prototyping largely achieved. This is due to stable 3DP materials, increasingly affordable metal AM and more reliable printers that are generally easy to operate. Coupled with this is increasing maturity of virtual tools that enables complex geometry generation (CAD), real time analysis (CAE), and some assessment of manufacturability of designs (CAPP) (e.g., simulation of injection moulding). The drawback for these is an over reliance on the tools on the part of a designer. A lack of understanding of the tools' limitations and practical experience can make design processes a matter of purgamentum init, exit purgamentum ${ }^{2}$. It is therefore necessary to train engineers to use these tools effectively and appropriately. Widespread use of AM and virtual prototyping tools also impacts performance of projects by greatly compressing development cycles over the last 15 years.

On prototype fidelity: The incorporation of these tools enables generation of higher fidelity prototypes earlier in the design process, allowing designers to try more possible solutions physically at higher fidelities compared to practice 15 years ago. Previously, designers would make more physical sketch prototypes (card/foam - informal prototypes), resulting in products being developed more incrementally, and before moving onto higher fidelity models that had much longer lead times. The downside of this is that current designers leave decision-making late as flexibility has given the opportunity to remain open, hence increasing levels of uncertainty. The use of higher fidelity, but lowcost prototyping techniques (such as 3DP) can lead to both cognitive inertia and sunk cost bias in the development cycle resulting in early stage design fixation and the potential for poor design decisions to be taken forward. This can also stifle innovative solutions, as the first cut can look like the final cut. It is therefore necessary to encourage low-fidelity prototypes that can answer questions about elements of the design problem rather than dealing with the whole.

On working with clients: These new technologies also impact work with clients, for whom increased ability to innovate internally enables clients to bring more mature designs to the table than 15 years ago. A drawback of this it that some clients don't understand the remaining effort required to go from a $3 \mathrm{D}$ printed prototype or $3 \mathrm{D}$ render to a design suitable for mass manufacture. These tools enable clients and other stakeholders to interact with higher fidelity boundary objects earlier in the process which facilitate valuable communication during product development. This also impacts the nature of projects which can be characterised by an increase in the development of new products, where small players are now involved in bringing products to market whereas previously only big companies could do this.

Impact of tools on designers: Designers are literate with 3DP and CAD and naturally use these in their processes. This increased reliance on technology and automation can tend to lead to a reduction of skills in more traditional methods such as sketching and sketch modelling. Digital literacy is increased but it can be at the expense of practical skills and fundamental know-how. Roles of designers and makers are increasingly blurred as digital manufacturing and design tools provide significant support where they lack expertise. The shift towards digital based tools prevents the possibility of situational backtalk in the concept generation phase. Sketches provide a designer with a continual feedback in the generation of their idea. It can also be used as a discussion point in a meeting and produced in very short time. Replacing this activity with a jump to high fidelity prototyping loses this feedback loop and prevents some of the creation and discussion.

To summarise, these validation interviews have verified widespread adoption of 3DP and virtual prototyping as demonstrated in the surveys. These provide increased capability and flexibility via

\footnotetext{
${ }^{2}$ rubbish in, rubbish out
} 
design support and provide better info, earlier, for both designers and clients. This supports innovation and quality, but delays decisions (designers), provides a crutch for fundamental knowledge (designers) and can misplace client expectations of effort to progress. Additionally, they identify highly compressed design cycles.

\subsection{Fit with existing models}

Section 5.2 and Section 5.1 demonstrated high levels of iteration and compressed timescales in industrial prototyping practice compared to 15 years ago, enabled by the widespread uptake of techniques which facilitate more collaborative working and rapid manufacture of physical prototypes. Iterations and working styles are therefore less formal now as there are fewer constraints in the process (now instant communication and manufacture in hours rather than weeks). Therefore, a movement from prescriptive to descriptive design models could be more useful in supporting designers?

This suggests that prototyping processes do not follow prescriptive models (e.g., Pahl and Beitz (2013)) but more closely resemble highly iterative descriptive model. Correspondingly, models defined as micro-abstract by Wynn and Clarkson (2018) such as Concept-Knowledge (CK) theory (Hatchuel and Weil, 2003) or Function-Behaviour-Structure (FBS) (Gero and Kannengiesser, 2004) might be better suited to describing industrial (design by) prototyping practice. In the case of CK theory, this is helpful for prototyping as in addition to recognising tangible design evolution in the concept space, it also formally recognises expansions and transformations within the knowledge space in the form, for example, of design rationale capture. Substantive value from prototyping activities occur in this knowledge space. Micro-abstract models, such as CK theory, therefore, provide value as they can help designers understand how these less tangible elements such as design rationale impact the design process.

\subsection{Improving prototyping and further work}

The presented snapshot suggests two ways in which prototyping processes could be improved. The first is via management of prototyping tools. Understanding the affordances of prototyping tools and their respective domains can enable selection of the right tool at the right time. This can be further extended to prototype tool management, which could enable selection of prototyping toolsets in order to provide product specific insights through the design process.

It is also evident, due to the high level of iteration between digital and physical domains (Q3), that prototyping can be improved through reduction in the effort (in terms of both time and skill) required to transition between physical and digital domains. Current transition processes are largely manual with for example, amendments being made manually to CAD models to mirror changes in a physical product. Synchronisation of these through rapid digitisation techniques, such as scan-to-CAD, could greatly improve this. In addition to expediting extant processes, seamless digital-physical transitions (twinning) would enable designers to work in the optimum medium and domain based upon their prototyping requirements rather than staying in one that is sub-optimal because time, skill or ability prevented a transition to another which could be more appropriate. Both of the above would add agility to the design process by supporting increased iteration, expediting development cycles and avoiding incorrect tooling. As such, both of these elements will be taken forward as further work.

\section{CONCLUSION}

This paper has presented and discussed a snapshot of prototyping practices at five design firms in the UK. This was constructed from survey results that featured questions on prototyping methods, materials, stakeholders and when these take place in their design processes. The snapshot identified similarities across companies in terms of: i) highly iterative processes; ii) prominent use of 3D printing (3DP), iii) a wide range of stakeholders involved in the process, iv) varying degrees of process formalisation, v) design working across both physical and digital domains; and, vi) evolution of design changes through the process moving from macro to meso to micro. When comparing our current snapshot with previous snapshots in literature it was found that processes and tools have evolved with 3DP and virtual prototyping reaching widespread adoption in SMEs. These have enabled greater innovation, process streamlining, and increased design support and capability. Iteration and client relationships remain important when prototyping, and adoption of new tools enable this to higher degrees than ever before. The snapshot was validated by additional design practitioners who also 
noted the whilst the identified evolution in prototyping practice yields greater flexibility it also compressed design cycles which can be detrimental. The snapshot and subsequent validation indicate that that descriptive models (such as CK theory and FBS) may be more appropriate than prescriptive models when characterising and supporting prototyping processes as they formally recognise the less tangible prototyping outcomes such as knowledge generation. The paper also proposes prototyping practice could be improved in two ways. First, via better understanding of the affordances of both prototyping media and domains in order to permit designers to select these based on their prototyping requirements. And second, through enabling twinning between digital and physical domains. Both of these areas are considered for further work.

\section{REFERENCES}

Arcuri, A. and Briand, L., 2011. A practical guide for using statistical tests to assess randomized algorithms in software engineering. 2011 33rd international conference on software engineering (icse). IEEE, pp.1-10.

Camburn, B., Viswanathan, V., Linsey, J., Anderson, D., Jensen, D., Crawford, R., Otto, K., and Wood, K., 2017. Design prototyping methods: state of the art in strategies, techniques, and guidelines. Design science, 3.

Coutts, E.R., Wodehouse, A., and Robertson, J., 2019. A comparison of contemporary prototyping methods. Proceedings of the design society: international conference on engineering design. Vol. 1, 1. Cambridge University Press, pp.1313-1322.

Elverum, C.W., Welo, T., and Tronvoll, S., 2016. Prototyping in new product development: strategy considerations. Procedia cirp, 50, pp.117-122.

Felton, H., Yon, J., and Hicks, B., 2020. Looks like but does it feel like? investigating the influence of mass properties on user perceptions of rapid prototypes. Proceedings of the design society: design conference. Vol. 1. Cambridge University Press, pp.1425-1434.

Gero, J.S. and Kannengiesser, U., 2004. The situated function-behaviour-structure framework. Design studies, 25(4), pp.373-391.

Graham, R., Crawley, E., and Mendelsohn, B.R., 2009. Engineering leadership education: a snapshot review of international good practice. White paper sponsored by the bernard $\mathrm{m}$. gordon-mit engineering leadership program.

Gregory, M.J., 1993. Integrated performance measurement: a review of current practice and emerging trends. International journal of production economics, 30, pp.281-296.

Hatchuel, A. and Weil, B., 2003. A new approach of innovative design: an introduction to ck theory. Ds 31: proceedings of iced 03 , the 14th international conference on engineering design, stockholm.

Hornbæk, K., 2006. Current practice in measuring usability: challenges to usability studies and research. International journal of human-computer studies, 64(2), pp.79-102.

Houde, S. and Hill, C., 1997. What do prototypes prototype? Handbook of human-computer interaction. Elsevier, pp.367-381.

Jensen, L.S., Özkil, A.G., Mortensen, N.H., et al., 2016. Prototypes in engineering design: definitions and strategies. Ds 84: proceedings of the design 2016 14th international design conference, pp.821-830.

Mathias, D., Hicks, B., Snider, C., Ranscombe, C., et al., 2018. Characterising the affordances and limitations of common prototyping techniques to support the early stages of product development. Ds 92: proceedings of the design 2018 15th international design conference, pp.1257-1268.

Mathias, D., Snider, C., Hicks, B., and Ranscombe, C., 2019. Accelerating product prototyping through hybrid methods: coupling 3d printing and lego. Design studies, 62, pp.68-99.

Pahl, G. and Beitz, W., 2013. Engineering design: a systematic approach. Springer Science \& Business Media.

Wall, M.B., Ulrich, K.T., and Flowers, W.C., 1992. Evaluating prototyping technologies for product design. Research in engineering design [Online], 3(3), pp.163-177. Available from: https://doi.org/10.1007/BF01580518.

Wynn, D.C. and Clarkson, P.J., 2018. Process models in design and development. Research in engineering design, 29(2), pp.161-202.

Yamaoka, J., Dogan, M.D., Bulovic, K., Saito, K., Kawahara, Y., Kakehi, Y., and Mueller, S., 2019. Foldtronics: creating $3 \mathrm{~d}$ objects with integrated electronics using foldable honeycomb structures. Proceedings of the 2019 chi conference on human factors in computing systems, pp.1-14.

Yeomans, S.G., Bouchlaghem, N.M., and El-Hamalawi, A., 2006. An evaluation of current collaborative prototyping practices within the aec industry. Automation in construction, 15(2), pp.139-149.

Zorriassatine, F., Wykes, C., Parkin, R., and Gindy, N., 2003. A survey of virtual prototyping techniques for mechanical product development. Proceedings of the institution of mechanical engineers, part b: journal of engineering manufacture, 217(4), pp.513-530. 